\title{
A Joint Return Policy for a Multi-Item Perishable Inventory Model with Deterministic Demands, Return and All-Units Discount
}

\author{
Dharma Lesmono \\ Department of Mathematics, \\ Universitas Katolik Parahyangan, Indonesia. \\ Corresponding author: jdharma@unpar.ac.id \\ Taufik Limansyah \\ Department of Mathematics, \\ Universitas Katolik Parahyangan, Indonesia. \\ E-mail: taufik.limansyah@unpar.ac.id \\ Neilshan Loedy \\ Department of Mathematics, \\ Universitas Katolik Parahyangan, Indonesia. \\ E-mail: neilshanloedy@gmail.com
}

(Received August 6, 2019; Accepted January 7, 2020)

\begin{abstract}
In this paper, we develop a multi-item perishable inventory model with deterministic demands, return and all-units discount. We consider a situation where a retailer sells several products to the customer and orders the products from one supplier. Demands are assumed to be deterministic following an inventory-dependent demand, and the supplier offers all-units discount to the retailer who has an opportunity to return unsold or deteriorated products to the supplier at a certain cost. In order to minimize the total cost for the retailer, the decision variables are the optimal return time and the optimal ordering quantity. Considering a multi-item case as an extension of the model by Setiawan et al. (2018) is the main contribution of this paper. We also develop an algorithm to find the optimal solution of the model. Numerical examples for three items are given to illustrate the model and a sensitivity analysis is performed to study the effect of the changes in parameter values on the optimal solution. We consider two scenarios, one with all-units discount and one with no discount. Within these two scenarios, we consider conditions of individual or joint return time for these three items. It is found that the individual return time with no discount gives the least total inventory cost in the numerical examples. Also, in general increasing the value of holding cost, deteriorating rate, return cost per unit and backorder cost will increase the total inventory cost in all scenarios.
\end{abstract}

Keywords- Joint return policy, Perishable inventory model, Multi-item, All-units discount.

\section{Introduction}

Inventory is one of the most important assets for a firm since in general it covers a high percentage of the firm's total capital. Therefore a good inventory management is crucial in order to make the firm's operation more flexible. Having less inventory can reduce cost but it can make customers dissatisfied due to the unmet demands. There are several functions inventory can serve such as anticipating demands from customers, and decoupling the production process, as a result of accepting quantity discounts offered by the supplier and to hedge against price changes and inflation (Heizer and Render, 2014).

For a manufacturing firm, inventory can take the form of raw materials, purchased parts and supplies, partially complete work in process, items being transported, and tools and equipment 
International Journal of Mathematical, Engineering and Management Sciences

Vol. 5, No. 3, 416-431, 2020

https://doi.org/10.33889/IJMEMS.2020.5.3.035

(Heizer and Render, 2014; Russell and Taylor III, 2014) classified inventory in terms of raw material, work-in-process, a maintenance/repair/operating supply inventory and a finished-goods inventory. There are some costs associated with inventory, the most common ones of which are ordering cost, carrying (holding) cost and shortage cost (Tersine, 1994; Russell and Taylor III, 2014; Shenoy and Rosas, 2018). Another cost that may be involved in the inventory cost is purchasing cost, although in most of the mathematical models this cost is not included since it is constant, unless there is a quantity discount involved. There are the two most important decisions in the inventory management: when to order and how many items to order. Making these two decisions will help a company in lowering its inventory cost.

Regarding quantity discount offered by the supplier, there are various types of quantity discount such as all-units discount, incremental discount or discount based on some continuous functions. However, in reality the all-units discount is the most common one, giving a reduced price if an item is purchased in larger quantities. Accepting the offer from the supplier to buy an intem in larger quantities can reduce the ordering cost, but at the same time the carrying cost will increase. Managing these two costs wisely through mathematical models can lower the inventory cost.

The situation becomes more complicated when dealing with perishable or deteriorating goods such as vegetables, fruit, bread, milk, fish, blood or chemicals. Ray (2017) defines deterioration as "change, damage, decay, spoilage, obsolescence and loss of utility or loss of original value in a commodity that results in the decreasing usefulness from the original one product". We ( $\mathrm{Li}$ et al., 2010) classifies deteriorating items into two categories, deteriorating that is due to time and due to the introduction of new technologies (computers, mobile phones, fashion, seasonal goods and so on). However, deterioration deals with items that have a short life cycle, generally speaking.

Demand for an item in many inventory models can be assumed to be either deterministic (and constant) such as the original Economic Order Quantity (EOQ) model, or probabilistic (having certain distributions) or else deterministic but has some features such as inventory-dependent demand or time-dependent demand or constant and time-dependent demand (Singh et al., 2017). The inventory-dependent demand feature where demand is influenced or depends on the number of the available inventory on the shelf has been widely modelled in the literature and in practice it is common in supermarket, retail industries, and seasonal dresses such as women's dresses or sports clothes during the selling season (Wolfe, 1968; Levin et al., 1972; Silver and Peterson, 1985).

In reality, a company can return some deteriorated items to the supplier at a certain cost, and the supplier will replace them with new items in the next replenishment. This situation along with deteriorating items and the nature of demands will affect two important decisions for a company, the optimal time and quantity to order. Regarding the return policy, the situation becomes complex if a company is dealing with multi-items. The company will face the problem whether to return an item individually or jointly to the supplier. Therefore, the optimal return time will be determined wisely in order to minimize the inventory cost.

In this paper we deal with a condition where a company sells items and the demands of these items that are having inventory-dependent demand features. We assume constant deterioration rate, allunits discounts and return policy. We propose a mathematical model to determine the optimal return time and the optimal order quantity that minimized the total inventory cost. The mathematical model and an algorithm to find the optimal solution for this problem form the main contribution of this paper. 
International Journal of Mathematical, Engineering and Management Sciences

Vol. 5, No. 3, 416-431, 2020

https://doi.org/10.33889/IJMEMS.2020.5.3.035

There are several references we used for the formulation of the inventory-dependent demand such as (Nagare and Dutta, 2012; Setiawan et al., 2018 and Loedy et al., 2018). In general, we extend the model of Setiawan et al. (2018) and Loedy et al. (2018) to accommodate the multi-item feature in our model and consider the individual and joint return policy. This is the main contribution of this paper. Also considering a multi-itme model with the above features is relevant to the real problem most of the smalll retailers have to deal with in their daily operation. We also provide an algorithm to find the optimal solution and numerical examples based on several scenarios encountered in our model. Sensitivity analysis is also performed in order to study the effect of changes in parameter values on the optimal solution.

\section{Literature Review}

As mentioned earlier, if a company wants to lower its inventory cost, it needs a good inventory management. One of the strategies in the inventory management is using mathematical models to describe the situation and find the optimal solution for the problem. Managing deteriorating or perishable goods has been an interesting research topic for decades. Comprehensive reviews on the perishable inventory theory can be found in (Nahmias, 1982; Li et al., 2010 and Ray, 2017). Perishable goods along with their variants such as the nature of demand, deterioration reduction, substitution products and pricing have attracted attention from researchers all over the world. Dye (2012) used particle swarm optimization in dealing with a finite-horizon deteriorating inventory model with two-phase pricing and time-varying demand. A quadratic demand rate and variable holding cost have been proposed by Kumar et al. (2012) in developing a model for deteriorating goods. Another model for the deteriorating inventory model has been developed by Yadav and Vats (2014) for time-dependent quadratic demand and constant holding cost with partial backlogging and inflation. Doung et al. (2015) proposed a multi-criteria inventory management system for perishable and substitutable products. They considered conditions such as multi-period life time, positive lead time and customer service level to build a model where each item is treated separately. When demand is price dependent and the cycle length is variable in the planning period a numerical study is conducted by Prasad Patnaik and Patnaik (2015) for deteriorating items. Sharmila and Uthayakumar (2016) studied a fuzzy inventory model with exponential demand when shortages are fully backlogged. An effort to reduce deterioration for perishable items was studied by FilinaDawidowicz and Postan (2016) using a generalized Wilson model. Meanwhile, Pervin et al. (2018) considered a model allowing shortage with time-dependent demand, time-varying holding cost and stochastic deterioration.

Another variant in the inventory models that has been developed is the nature of demand, such as inventory-dependent demand and time-dependent demand. The inventory-dependent demand was first studied by many researchers, among others (Wolfe, 1968; Levin et al., 1972 and Silver and Peterson, 1985). In the last few decades, many papers deal with this inventory-dependent demand, such as Baker and Urban (1988a) which proposed single-period inventory demand models where demand is of a polynomial function form to maximize the total profit. By assuming instantaneous replenishments and using the same polynomial function form, in the same year, Baker and Urban (1998b) developed a continuous and deterministic inventory model. Incorporating inventorydependent demand, variable holding cost and shortages to build a mathematical model were the focus of Rathod and Bhathawala (2013). They assumed that the holding cost is linear with the quantity in storage. In 2017, Singh et al. (2017) considered constant and time-dependent linear demand rate to build a mathematical model to find the optimal policy for deteriorating items. They assumed that the deterioration rate is time-proportional. Kavithapriya and Senbagam (2018) 
International Journal of Mathematical, Engineering and Management Sciences

Vol. 5, No. 3, 416-431, 2020

https://doi.org/10.33889/IJMEMS.2020.5.3.035

developed a mathematical model for quadratic time-dependent demand, two parameter Weibull deterioration rate and shortage.

Table 1. Position of this research

\begin{tabular}{|c|c|c|c|c|c|}
\hline Author(s) & Deterioration & $\begin{array}{l}\text { Demand depends } \\
\text { on }\end{array}$ & $\begin{array}{l}\text { Single } \\
\text { Item }\end{array}$ & $\begin{array}{l}\text { Multi } \\
\text { Item }\end{array}$ & Additional Features \\
\hline Baker and Urban (1988a) & & inventory level & $\sqrt{ }$ & & \\
\hline Baker and Urban (1988b) & & inventory level & & $\sqrt{ }$ & \\
\hline $\begin{array}{l}\text { Rathod. and Bhathawala } \\
\text { (2013) }\end{array}$ & & inventory level & $\sqrt{ }$ & & $\begin{array}{c}\text { variable holding cost and } \\
\text { shortages }\end{array}$ \\
\hline Li et al. (2010) & $\sqrt{ }$ & & & & \\
\hline Duong et al. (2015) & $\sqrt{ }$ & & & $\sqrt{ }$ & \\
\hline Ray (2017) & $\sqrt{ }$ & & & & \\
\hline $\begin{array}{l}\text { Filina-Dawidowicz and Postan } \\
\text { (2016) }\end{array}$ & $\sqrt{ }$ & & $\sqrt{ }$ & & $\begin{array}{l}\text { additional cost for } \\
\text { deterioration reduction }\end{array}$ \\
\hline Chang (2004) & $\sqrt{ }$ & inventory level & $\sqrt{ }$ & & non-linear holding cost \\
\hline Chang et al. (2010) & $\sqrt{ }$ & $\begin{array}{l}\text { inventory level } \\
\text { and price }\end{array}$ & $\sqrt{ }$ & & limited shelf space \\
\hline Dye (2012) & $\sqrt{ }$ & time & & & \\
\hline Singh et al. (2017) & $\sqrt{ }$ & time & & & \\
\hline Kumar et al. (2012) & $\sqrt{ }$ & quadratic time & $\sqrt{ }$ & & variable holding cost \\
\hline Yadav and Vats (2014) & $\sqrt{ }$ & quadratic time & $\sqrt{ }$ & & $\begin{array}{l}\text { constant holding cost, } \\
\text { partial blocking, and } \\
\text { inflation }\end{array}$ \\
\hline $\begin{array}{l}\text { Kavithapriya and Senbagam } \\
\text { (2018) }\end{array}$ & $\sqrt{ }$ & quadratic time & $\sqrt{ }$ & & shortages \\
\hline Mishra et al. (2013) & $\sqrt{ }$ & time & $\sqrt{ }$ & & time-varying holding cost \\
\hline Pervin et al. (2018) & $\sqrt{ }$ & time & $\sqrt{ }$ & & $\begin{array}{l}\text { shortages, time-varying } \\
\text { holding cost }\end{array}$ \\
\hline $\begin{array}{l}\text { Prasad Patnaik and Patnaik. } \\
\text { (2015) }\end{array}$ & $\sqrt{ }$ & selling price & $\sqrt{ }$ & & \\
\hline $\begin{array}{l}\text { Sharmila and Uthayakumar } \\
\text { (2015) }\end{array}$ & $\sqrt{ }$ & $\begin{array}{l}\text { exponential } \\
\text { demand }\end{array}$ & $\sqrt{ }$ & & shortages \\
\hline Nagare and Dutta (2012) & $\sqrt{ }$ & inventory level & $\sqrt{ }$ & & \\
\hline Setiawan et al. (2018) & $\sqrt{ }$ & & $\sqrt{ }$ & & return policy \\
\hline Loedy et al. (2018) & $\sqrt{ }$ & inventory level & $\sqrt{ }$ & & $\begin{array}{l}\text { all-units discount, return } \\
\text { policy }\end{array}$ \\
\hline This paper & $\sqrt{ }$ & inventory level & & $\sqrt{ }$ & $\begin{array}{l}\text { all-units discount, return } \\
\text { policy }\end{array}$ \\
\hline
\end{tabular}

Incorporating deteriorating items and inventory-dependent demand have also been studied for many years. An inventory model with nonlinear holding cost and inventory-dependent demand was studied by Chang (2004). Meanwhile, Chang et al. (2010) developed a model by adding pricedependent demand and limited shelf space. Nagare and Dutta (2012) considered a continuous review model, while Mishra et al. (2013) developed a model with partial backlogging, time-varying holding cost and Weibull deteriorating rate. Considering an economic production quantity (EPQ), Kaliraman et al. (2015) proposed a model with Weibull deterioration and no shortage, while Uthayakhumar and Tharani (2017) proposed an EPQ model for time-dependent demand with rework and multiple production setups. Setiawan et al. (2018) considered a model with constant deterioration rate and return for deteriorated or unsold items.

The contribution of this paper lies in developing a mathematical model for a multi-item deteriorating inventory with inventory-dependent demand, return and all-units discount. The decision variables in the model are the optimal return time and order quantity that minimize the 
International Journal of Mathematical, Engineering and Management Sciences

Vol. 5, No. 3, 416-431, 2020

https://doi.org/10.33889/IJMEMS.2020.5.3.035

total inventory cost. We assume that joint return time comes from the joint replenishment policy and individual return time as a result of individual replenishment policy. There is only one supplier in our model setting. The position of this reseach along with its contribution is depicted in Table 1. Our paper differs with other papers in terms of the application of multi-item inventory problem with deterioration factor, inventory-dependent demand, return and all-units discount. To the best of our knowledge, combining all factors in the model is the contribution of this paper and indeed it illustrates the real problem most of the small retailers face in their operation here.

The organization of this paper is as follows. In the next section, we introduce notation and model formulation which is mainly derived from Setiawan et al. (2018) and Loedy et al. (2018). A proposed algorithm to find the optimal solution is also part of the next section. We provide a numerical example in Section 4 along with its optimal solution and analysis. Section 5 is devoted to the sensitivity analysis where we study the effect of changes in parameter values to the optimal solution. Conclusions and further research directions are relegated in the last section.

\section{Assumptions, Model Formulation and Algorithm}

In developing our model, we use the following notations. The notations are mainly derived from Setiawan et al. (2018) and Loedy et al. (2018) for single item and constant deteriorating rate, while in this context we consider multi-item.

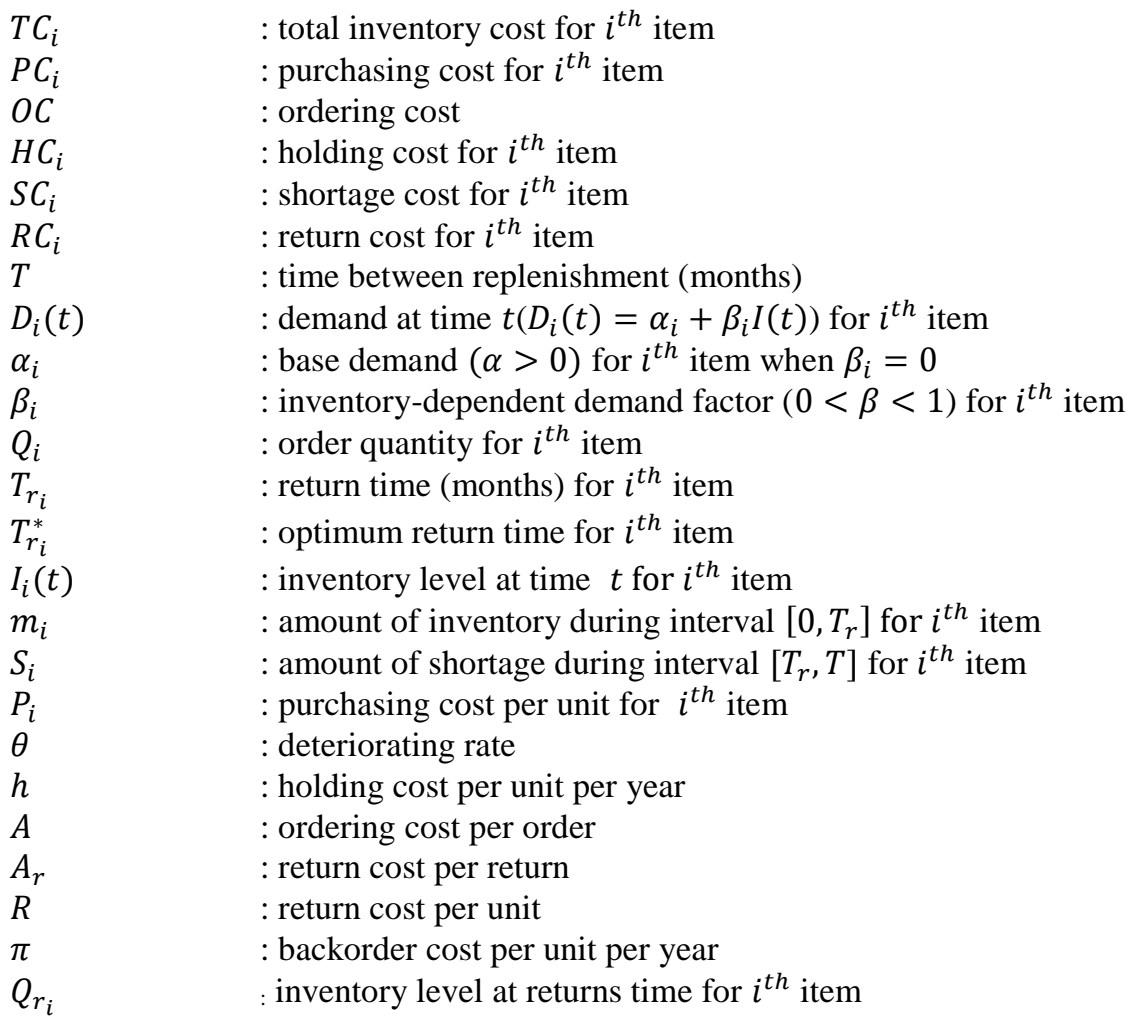

We also have the following assumptions in developing our model:

(i) There is only a single supplier. 
(ii) There is no inventory at hand after the return time for each item, since all unsold or deteriorated items are returned to the supplier and the returned amount will be available in the next shipment.

(iii) The number of returned items is $10 \%$ of the order quantity of these items.

(iv) Considering scenarios with joint return time, there are only two possibilities we consider, either all items ordered with all-units discount or without all-units discount.

(v) When items are jointly replenished, the unsold or deteriorated items should also be jointly returned to the supplier.

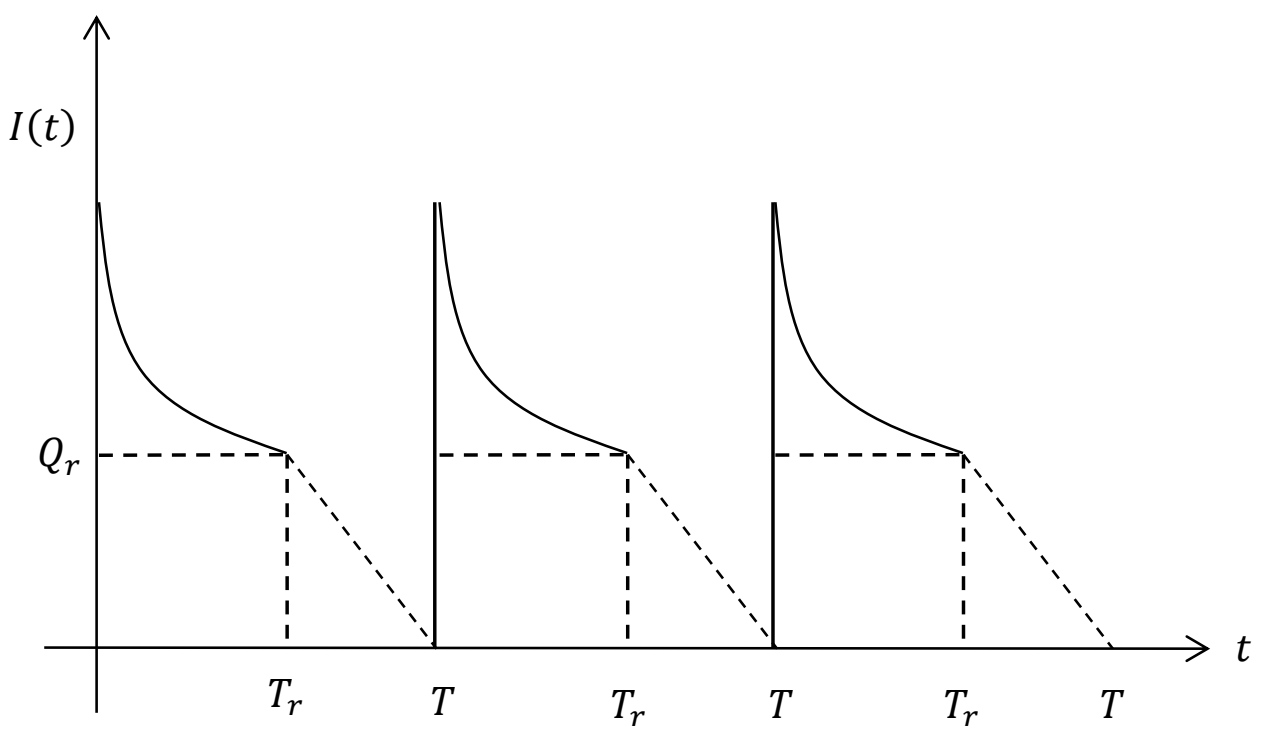

Figure 1. Inventory level

For each item, $\mathrm{i}=1,2, \ldots, \mathrm{n}$ demand for the $\mathrm{i}^{\text {th }}$ item are modeled by the following inventorydependent demand function.

$D_{i}(t)= \begin{cases}\alpha_{i}+\beta_{i} I(t) & , 0 \leq t \leq T_{r_{i}} \\ B_{i} & , T_{r_{i}} \leq t \leq T\end{cases}$

Demand for the $\mathrm{i}^{\text {th }}$ item at time $\mathrm{t}$ for $0 \leq t \leq T_{r_{i}}$ is a function of the number of inventory at time $\mathrm{t}$, $\mathrm{I}(\mathrm{t})$ with a dependent-demand factor $\beta_{i}$ and base demand $\alpha_{i}$. When $T_{r_{i}} \leq t \leq T$, demand for item $\mathrm{i}$ at time $\mathrm{t}$ is a constant, $B_{i}$.

Figure 1 gives a representation of inventory level over time. When $0 \leq t \leq T_{r}$, inventory depletes due to demand and deterioration. Then between $T_{r}$ and $\mathrm{T}$ there is no invetory at hand and backorder condition occurs when demand comes. At time $t=T_{r}$ all unsold or deteriorated items are returned to the supplier, and the supplier will replace them at the next shipment. This cycle is repeated time over time.

The following first order differential equation describes the rate of change of inventory of item $i$ at time t over time during $0 \leq t \leq T$.

$\frac{d I_{i}(t)}{d t}+\theta I_{i}(t)=-D_{i}(t)$ 
International Journal of Mathematical, Engineering and Management Sciences

Vol. 5, No. 3, 416-431, 2020

https://doi.org/10.33889/IJMEMS.2020.5.3.035

The inventory decreases because demand from the customer and deterioration rate. The differential equation represents the rate at which the inventory decreases. Inserting the function for inventorydependent demand we have the following differential equations.

$\frac{d I_{i}(t)}{d t}=-\theta I_{i}(t)-\left(\alpha_{i}+\beta_{i} I_{i}(t)\right), 0 \leq t \leq T_{r_{i}}$

$\frac{d I_{i}(t)}{d t}=-\theta I_{i}(t)-B_{i}, T_{r_{i}} \leq t \leq T$

We assume that there is no inventory at hand just after the return time (for item i) $T_{r_{i}}$ since all the remaining inventory is returned to the supplier to be replaced with new ones on the next replenishment. Therefore we have $I\left(T_{r_{i}}\right)=0$ and the inventory at time $t, I_{i}(t)$ for $T_{r_{i}} \leq t \leq T$ is given by

$\frac{d I_{i}(t)}{d t}=-B_{i}$

$I_{i}(t)=B_{i}\left(T_{r_{i}}-t\right)$

However, just before $T_{r_{i}}$, there is a certain amount of inventory $Q_{r_{i}}$ that will be returned to the supplier. This gives another boundary condition of $I\left(T_{r_{i}}\right)=Q_{r_{i}}$ for $0 \leq t \leq T_{r}$, and consequently we have

$\frac{d I_{i}(t)}{d t}=-\theta I_{i}(t)-\left(\alpha_{i}+\beta_{i} I_{i}(t)\right)$

The solution of these differential equations is given by

$I_{i}(t)=-\frac{\alpha_{i}}{\beta_{i}+\theta}+\frac{e^{-\left(\beta_{i}+\theta\right) t}\left(Q_{r_{i}}+\frac{\alpha_{i}}{\beta_{i}+\theta}\right)}{e^{-\left(\beta_{i}+\theta\right) T} r_{i}}$

The number of inventory items at the beginning of the cycle is $Q_{i}$ minus the shortage during $T_{r_{i}} \leq$ $t \leq T$, so $I_{i}(0)=Q_{i}-B_{i}\left(T_{r_{i}}-T\right)$. Then, we have the following order quantity $Q_{i}$

$Q_{i}=-\frac{\alpha_{i}}{\beta_{i}+\theta}+\frac{e^{-\left(\beta_{i}+\theta\right) t}\left(Q_{r_{i}}+\frac{\alpha_{i}}{\beta_{i}+\theta}\right)}{e^{-\left(\beta_{i}+\theta\right) T_{r_{i}}}}+B_{i}\left(T-T_{r_{i}}\right)$

Assuming that there are $10 \%$ of items i returned to the supplier, we can calculate the number of returned goods as follows.

$10 Q_{r_{i}}=-\frac{\alpha_{i}}{\beta_{i}+\theta}+\frac{e^{-\left(\beta_{i}+\theta\right) t}\left(Q_{r_{i}}+\frac{\alpha_{i}}{\beta_{i}+\theta}\right)}{e^{-\left(\beta_{i}+\theta\right) T r_{i}}}+B_{i}\left(T-T_{r_{i}}\right)$

$Q_{r_{i}}=\frac{B_{i} T e^{-\left(\beta_{i}+\theta\right) T} r_{i} \beta_{i}+B_{i} T e^{-\left(\beta_{i}+\theta\right) T} r_{i \theta-\alpha_{i}} e^{-\left(\beta_{i}+\theta\right) T} r_{\left.i+\alpha_{i}\right)}}{10 e^{-\left(\beta_{i}+\theta\right) T} r_{i} \beta_{i}+10 e^{-\left(\beta_{i}+\theta\right) T} r_{i} \theta-\beta_{i}-\theta}$

The number of inventory items during $\left[0, T_{r_{i}}\right]$ and the number of shortages (that are backordered) during $\left[T_{r_{i}}, T\right]$ is calculated using the following formula

$m_{i}=\int_{0}^{T_{r_{i}}} I_{i}(t) d t$ 
International Journal of Mathematical, Engineering and Management Sciences

Vol. 5, No. 3, 416-431, 2020

https://doi.org/10.33889/IJMEMS.2020.5.3.035

$S_{i}=B_{i} T_{r_{i}}\left(T-T_{r_{i}}\right)-\frac{B_{i}\left(T^{2}-T_{r_{i}}^{2}\right)}{2}$

Based on the above calculations, we are now able to calculate the total inventory cost that includes purchasing, ordering, holding, shortage (backorder) and return costs.

Purchasing cost is defined as the purchase cost per unit times the quantity of purchased item, namely

$P C_{i}=\frac{T \cdot P_{i} \cdot Q_{i}}{12}$

The ordering cost usually does not depend on the number of items ordered, but on the order frequency. So the formulation is as follows.

$O C=\frac{12 A}{T}$

In formulating the holding cost, we need to consider number of stored items $(m)$ and the duration of storage $(T)$. This cost is formulated as follows.

$H C=\frac{T \cdot h \cdot m_{i}}{12}$

Shortage cost occurs when a firm does not have inventory when demands come in. In our model, we assume that all shortages are backlogged and we have the following formulation for the shortage cost.

$S C_{i}=\frac{-12 \pi\left(B_{i} T_{r_{i}}\left(T-T_{r_{i}}\right)-\frac{B_{i}\left(T^{2}-T_{r_{i}}^{2}\right)}{2}\right)}{T}$

Returning some deteriorated or unsold items to the supplier will induce some cost. This cost is called the return cost in our model and the quantity is given by

$R C_{i}=12\left(\frac{A_{r}+Q_{r_{i}} R}{T}\right)$

The decision variables in our model are the optimal order quantity and return time that minimize the total inventory cost. We consider two strategies, namely individual return time and joint return time policies to minimize the total inventory cost. The formulations of the total inventory cost for individual return time and joint return time for $i=1,2, \ldots, n$ are given by the following formula assuming that joint replenishment policy induces joint return time and individual replenishment policy will be followed by individual return time to the single supplier.

Individual Return Time

$T C=n O C+\sum_{i=1}^{n}\left(P C_{i}+H C_{i}+S C_{i}+R C_{i}\right)$

\section{Joint Return Time}

$T C=O C-\frac{12(n-1)}{T} A_{r}+\sum_{i=1}^{n}\left(P C_{i}+H C_{i}+S C_{i}+R C_{i}\right)$

When items are jointly replenished, the ordering cost only occurred once and the frequency of returning the unsold or deteriorated item will also be reduced. This explains the difference between the above formulas for individual return time and joint return time policy. 
International Journal of Mathematical, Engineering and Management Sciences

Vol. 5, No. 3, 416-431, 2020

https://doi.org/10.33889/IJMEMS.2020.5.3.035

We also incorporate the all-units discount offer from the supplier in our model. An algorithm to find the optimal solution of our model considering all the conditions we mentioned is given in Figure 2. First, we evaluate the value of $T_{r_{i}}$ of each level of purchase price $P_{i}$ by taking the first derivative of TC with respect to $T_{r_{i}}$ and equal them to zero. Then we evaluate the order quantity $\mathrm{Q}_{\mathrm{i}}$, whether it is valid or not (according to the all-units discount scheme) and finally we compare the total inventory cost for the joint return time and individual return time. By joint return time, all deteriorated or unsold items are returned at the same time $\left(\mathrm{T}_{\mathrm{r}}\right)$ while this $\mathrm{T}_{\mathrm{r}}$ can be chosen as the same one as one of the $T_{r_{i}}$. For individual return time, we use $T_{r_{i}}$ for each item.

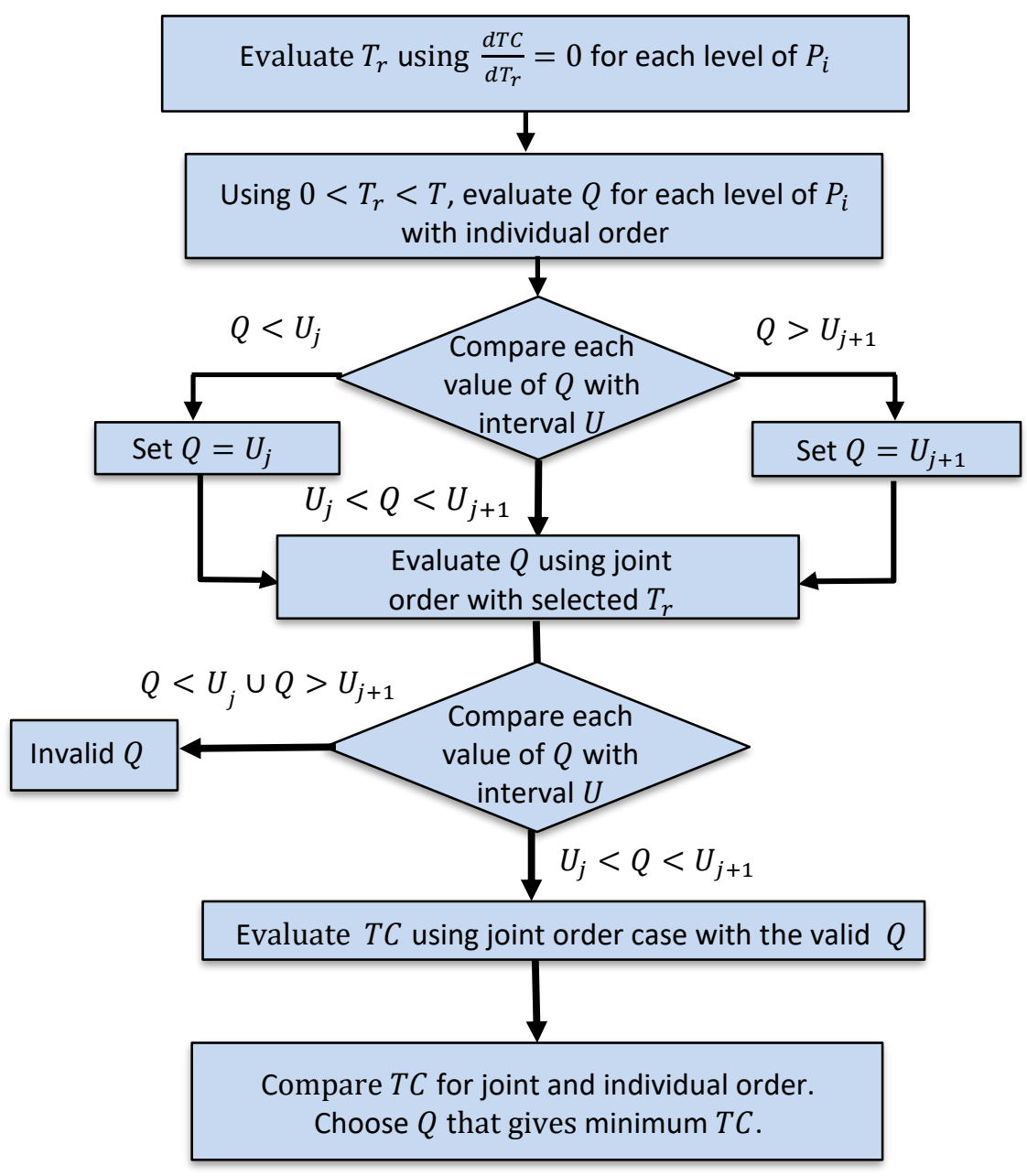

Figure 2. Algorithm to find the optimal solution

\section{Numerical Example}

We consider the three-item example below in order to illustrate our model. The parameters we use are the following 
International Journal of Mathematical, Engineering and Management Sciences

Vol. 5, No. 3, 416-431, 2020

https://doi.org/10.33889/IJMEMS.2020.5.3.035

$$
P_{1}=\left\{\begin{array}{l}
\$ 6, \quad Q \leq 10,000 \\
\$ 4, \quad Q>10,000
\end{array}, \quad P_{2}=\left\{\begin{array}{c}
\$ 6, \quad Q \leq 10,000 \\
\$ 3.5, \quad Q>10,000
\end{array}, P_{3}=\left\{\begin{array}{c}
\$ 6, \quad Q \leq 10,000 \\
\$ 4.5, \quad Q>10,000
\end{array}\right.\right.\right.
$$

$T=6$ months, $\alpha_{1}=120$ units, $\alpha_{2}=115$ units, $\alpha_{3}=110$ units, $A=\$ 10, h=\$ 5, \pi=\$ 2, R=\$ 2$, $A_{r}=\$ 10, \beta_{1}=0.165, \beta_{2}=0.18, \beta_{3}=0.175, \theta=0.2, B_{1}=4000$ units, $B_{2}=4500$ units, and $B_{3}=3750$ units.

Considering individual and joint return time we develop four scenarios, namely individual return time for Scenario 1 and joint return time for Scenario 2, 3 and 4. Within each scenario, we also consider two conditions, $\mathrm{a}$ and $\mathrm{b}$. Condition a for cases with all-units discount and condition $\mathrm{b}$ for cases without all-units discount. The difference among Scenario 2, 3 and 4 lies in the joint return time. The joint return time is chosen to be the same as the return time for item 1, item 2 and item 3 for Scenario 2, Scenario 3 and Scenario 4 respectively. Results for the above numerical example are given in Table 2 .

Table 2. Scenarios and optimal solution

\begin{tabular}{|c|c|c|c|c|c|c|c|c|c|c|c|c|c|}
\hline \multicolumn{14}{|c|}{ First Scenario } \\
\hline \multirow[b]{2}{*}{$T_{r_{1}}$} & \multirow{2}{*}{$T_{r_{2}}$} & \multirow{2}{*}{$T_{r_{3}}$} & \multicolumn{4}{|c|}{$a$} & \multirow{2}{*}{$T_{r_{1}}$} & \multirow{2}{*}{$T_{r_{2}}$} & \multirow{2}{*}{$T_{r_{3}}$} & \multicolumn{4}{|c|}{$b$} \\
\hline & & & $T C$ & $Q_{r_{1}}$ & $Q_{r_{2}}$ & $Q_{r_{3}}$ & & & & $T C$ & $Q_{r_{1}}$ & $Q_{r_{2}}$ & $Q_{r_{3}}$ \\
\hline 3.90 & 3.72 & 3.76 & 173,377 & 932 & 935 & 856 & 4.99 & 4.63 & 5.01 & 196,416 & 1,000 & 1,000 & 1,000 \\
\hline \multicolumn{14}{|c|}{ Second Scenario } \\
\hline \multirow{2}{*}{\multicolumn{3}{|c|}{$T_{r_{1}}$}} & \multicolumn{4}{|c|}{$a$} & \multirow{2}{*}{\multicolumn{3}{|c|}{$T_{r_{1}}$}} & \multicolumn{4}{|c|}{$b$} \\
\hline & & & $T C$ & $Q_{r_{1}}$ & $Q_{r_{2}}$ & $Q_{r_{3}}$ & & & & $T C$ & $Q_{r_{1}}$ & $Q_{r_{2}}$ & $Q_{r_{3}}$ \\
\hline & 3.90 & & 173,787 & 932 & 935 & 855 & & 4.99 & & Invalid & 1,000 & 1,116 & 992 \\
\hline \multicolumn{14}{|c|}{ Third Scenario } \\
\hline \multirow{2}{*}{\multicolumn{3}{|c|}{$T_{r_{2}}$}} & \multicolumn{4}{|c|}{$a$} & \multirow{2}{*}{\multicolumn{3}{|c|}{$T_{r_{2}}$}} & \multicolumn{4}{|c|}{$b$} \\
\hline & & & $T C$ & $Q_{r_{1}}$ & $Q_{r_{2}}$ & $Q_{r_{3}}$ & & & & $T C$ & $Q_{r_{1}}$ & $Q_{r_{2}}$ & $Q_{r_{3}}$ \\
\hline \multicolumn{3}{|c|}{3.72} & 173,585 & 939 & 935 & 857 & \multicolumn{3}{|c|}{4.63} & Invalid & 945 & 1,000 & 903 \\
\hline \multicolumn{14}{|c|}{ Fourth Scenario } \\
\hline \multirow{2}{*}{\multicolumn{3}{|c|}{$T_{r_{3}}$}} & \multicolumn{4}{|c|}{$a$} & \multirow{2}{*}{\multicolumn{3}{|c|}{$T_{r_{3}}$}} & \multicolumn{4}{|c|}{$b$} \\
\hline & & & $T C$ & $Q_{r_{1}}$ & $Q_{r_{2}}$ & $Q_{r_{3}}$ & & & & $T C$ & $Q_{r_{1}}$ & $Q_{r_{2}}$ & $Q_{r_{3}}$ \\
\hline & 3.76 & & 173,486 & 937 & 934 & 856 & & 5.01 & & 209,977 & 1,006 & 1,127 & 1,000 \\
\hline
\end{tabular}

Comparing the case without all-units discount (condition a for each scenario), we can see that the first scenario gives the total cost of $\$ 173,377$, as the most minimal among other scenarios. This means that choosing the return time individually for the cases without discount is superior compared with other scenarios by joining the return time to item 1, item 2 or item 3 . However, for the case with all-units discount, again the first scenario, the individual return time gives the least total cost of $\$ 196,416$. Comparing all scenarios with and without all-units discount, the first scenario with no discount gives the least total inventory cost of $\$ 173,377$. This means that individual return time with no all-units discount for each item is superior compared to other 
International Journal of Mathematical, Engineering and Management Sciences

Vol. 5, No. 3, 416-431, 2020

https://doi.org/10.33889/IJMEMS.2020.5.3.035

scenarios based on the parameters we chose for this numerical experiment. Some scenarios give invalid total inventory cost (in fact this occurs in the number of quantity ordered or quantity returned) since in those cases there is an optimal order quantity that is less than 10,000 units (as a condition to obtain a cheaper price in the all-units discount scheme). For example in Scenario $2 b$, the total inventory cost is labeled "invalid" since the number of returned item for at least one item is invalid since it is below 1,000 units (to get all-units discount, it should be at least 1,000 units).This is due to our fourth assumption where all items should be ordered together either with or without all-units discount. When one item is ordered with all-units discount, then the other two items should also be ordered with all-units discount, forcing higher order quantity for these two items. Please note that in Table 1 , we give the value of $\mathrm{Q}_{\mathrm{r}}$, the quantity of returned goods based on the assumption that $10 \%$ of the ordered goods will be returned to the supplier due to deterioration or remaining unsold. The optimal order quantity $Q$ is just 10 times the value of $Q_{r}$.

From the managerial point of view, results presented in Table 2 give the interesting insight that the individual return time is preferable to joint retun time, although it cannot be generalized that the individual return time is always preferable. By individual return time, the retailer has more freedom to return the item according to its optimal return time compared to the joint return time. Also, it is found from Table 1 that all-units discount offered by the supplier does not guarantee the retailer to increase its order quantity since the incentive for the discount especially in the ordering and shortage costs cannot offset for the increase in the holding and purchasing costs. Therefore, the individual return time without all-units discount is preferable to individual or joint return time with all-units discount.

When we only consider one item (item 1), the results are given in Table 3 below. We consider conditions without all-units discount (a) and with all-units discount (b), and we found that the allunits discount scheme offered by the supplier does not quite attractive making the condition without all-units discount is favorable with a total inventory cost of $\$ 59,243$. The optimal returned quantity of the condition (a) is less than the one in condition (b), and also the optimal order quantity. The optimal return time for condition (a) is also shorter than in condition (b) due to the less optimal order quantity.

Table 3. Scenarios and optimal solution for one item (Item 1)

\begin{tabular}{|c|c|c|c|c|c|}
\hline \multicolumn{9}{|c|}{ First Scenario } \\
\hline \multirow{2}{*}{$T_{r_{1}}$} & \multicolumn{2}{|c|}{$a$} & \multirow{2}{*}{$T_{r_{1}}$} & \multicolumn{2}{c|}{$b$} \\
\cline { 2 - 3 } \cline { 5 - 6 } & $T C$ & $Q_{r_{1}}$ & & $T C$ & $Q_{r_{1}}$ \\
\hline 3.90 & 59,243 & 932 & 4.99 & 66,201 & 1,000 \\
\hline
\end{tabular}

\section{Sensitivity Analysis}

We perform a sensitivity analysis to study the effect of changes in parameter values on the optimal solution. In each scenario we change the parameter value from $-15 \%$ to $+15 \%$ from the original value we considered in Section 4. There are only four parameters under consideration, namely holding cost per unit per year, deteriorating rate, return cost per unit and backorder cost per unit per year. We only change one parameter value at a time while all other parameter values remain 
International Journal of Mathematical, Engineering and Management Sciences

Vol. 5, No. 3, 416-431, 2020

https://doi.org/10.33889/IJMEMS.2020.5.3.035

the same as in Section 4. Results of this sensitivity analysis are given in Table 4. We also provide the value of $Q_{r}$ in Table 2, not $Q$. The value of $Q$ is just 10 times $Q_{r}$.

Generally speaking, increasing the value of holding cost, deteriorating rate, return cost per unit and backorder cost will increase the total inventory cost in all scenarios. For the individual return time (Scenario 1), the all-units discount gives a higher total inventory cost than no discount. We can see that for all-units discount in Scenario 1, all items are ordered with all-units discount, making the amount of returned goods 1,000 units and making the total cost higher compared to cases without discount. Note that decreasing the deterioration rate to $-15 \%$ will make the condition with all-units discount in the Scenario 1 become invalid. This is due to our fourth assumption that all items should be ordered either with or without discount, meaning that the quantity ordered should be higher than 10,000 units (or the quantity returned is more than 1,000 units).

Table 4. Sensitivity analysis

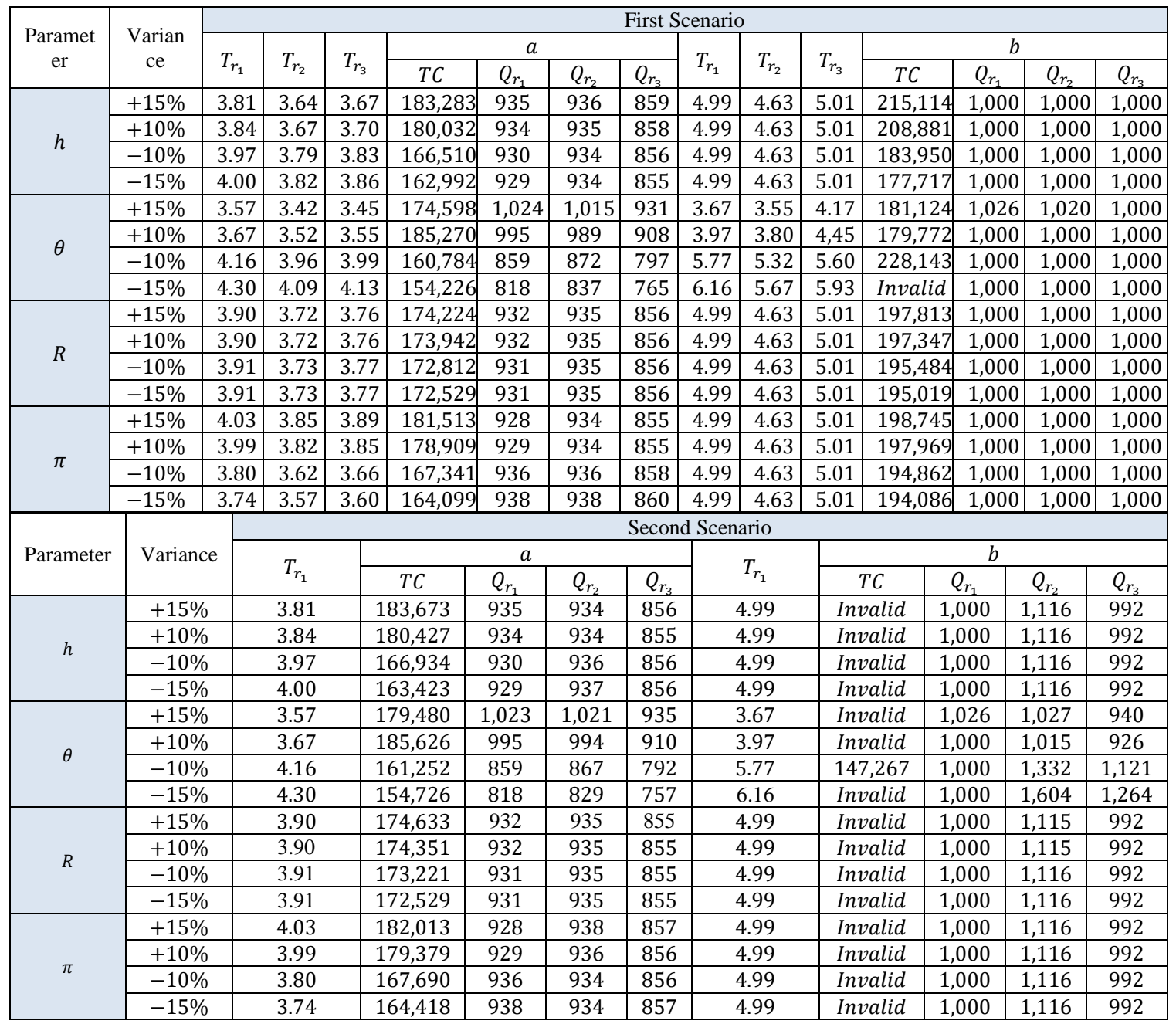


International Journal of Mathematical, Engineering and Management Sciences

Vol. 5, No. 3, 416-431, 2020

https://doi.org/10.33889/IJMEMS.2020.5.3.035

Table 4 continued ...

\begin{tabular}{|c|c|c|c|c|c|c|c|c|c|c|c|}
\hline \multirow{3}{*}{ Parameter } & \multirow{3}{*}{ Variance } & \multicolumn{10}{|c|}{ Third Scenario } \\
\hline & & \multirow{2}{*}{$T_{r_{2}}$} & \multicolumn{4}{|c|}{$a$} & \multirow{2}{*}{$T_{r_{2}}$} & \multicolumn{4}{|c|}{$b$} \\
\hline & & & $T C$ & $Q_{r_{1}}$ & $Q_{r_{2}}$ & $Q_{r_{3}}$ & & $T C$ & $Q_{r_{1}}$ & $Q_{r_{2}}$ & $Q_{r_{3}}$ \\
\hline \multirow{4}{*}{$h$} & $+15 \%$ & 3.64 & 183,479 & 944 & 936 & 859 & 4.63 & Invalid & 945 & 1,000 & 903 \\
\hline & $+10 \%$ & 3.67 & 180,232 & 942 & 935 & 858 & 4.63 & Invalid & 945 & 1,000 & 903 \\
\hline & $-10 \%$ & 3.79 & 166,725 & 936 & 934 & 856 & 4.63 & Invalid & 945 & 1,000 & 903 \\
\hline & $-15 \%$ & 3.82 & 163,211 & 935 & 934 & 856 & 4.63 & Invalid & 945 & 1,000 & 903 \\
\hline \multirow{4}{*}{$\theta$} & $+15 \%$ & 3.42 & 180,078 & 1,025 & 1,015 & 931 & 3.55 & Invalid & 1,024 & 1,019 & 934 \\
\hline & $+10 \%$ & 3.52 & 185,451 & 998 & 990 & 908 & 3.80 & Invalid & 996 & 1,000 & 915 \\
\hline & $-10 \%$ & 3.96 & 161,018 & 872 & 872 & 799 & 5.32 & Invalid & 874 & 1,000 & 885 \\
\hline & $-15 \%$ & 4.08 & 154,474 & 836 & 837 & 767 & 5.67 & Invalid & 823 & 1,000 & 871 \\
\hline \multirow{4}{*}{$R$} & $+15 \%$ & 3.72 & 174,431 & 939 & 935 & 857 & 4.63 & Invalid & 945 & 1,000 & 903 \\
\hline & $+10 \%$ & 3.72 & 174,149 & 939 & 935 & 857 & 4.63 & Invalid & 945 & 1,000 & 903 \\
\hline & $-10 \%$ & 3.73 & 173,019 & 939 & 935 & 857 & 4.63 & Invalid & 945 & 1,000 & 903 \\
\hline & $-15 \%$ & 3.73 & 172,736 & 939 & 935 & 857 & 4.63 & Invalid & 945 & 1,000 & 903 \\
\hline \multirow{4}{*}{$\pi$} & $+15 \%$ & 3.85 & 181,772 & 933 & 934 & 855 & 4.63 & Invalid & 945 & 1,000 & 903 \\
\hline & $+10 \%$ & 3.82 & 179,151 & 935 & 934 & 856 & 4.63 & Invalid & 945 & 1,000 & 903 \\
\hline & $-10 \%$ & 3.62 & 167,514 & 944 & 936 & 859 & 4.63 & Invalid & 945 & 1,000 & 903 \\
\hline & $-15 \%$ & 3.57 & 164,255 & 948 & 938 & 861 & 4.63 & Invalid & 945 & 1,000 & 903 \\
\hline \multirow{3}{*}{ parameter } & \multirow{3}{*}{ Variance } & \multicolumn{10}{|c|}{ Fourth Scenario } \\
\hline & & \multirow{2}{*}{$T_{r_{3}}$} & \multicolumn{4}{|c|}{$a$} & \multirow{2}{*}{$T_{r_{3}}$} & \multicolumn{4}{|c|}{$b$} \\
\hline & & & $T C$ & $Q_{r_{1}}$ & $Q_{r_{2}}$ & $Q_{r_{3}}$ & & $T C$ & $Q_{r_{1}}$ & $Q_{r_{2}}$ & $Q_{r_{3}}$ \\
\hline \multirow{4}{*}{$h$} & $+15 \%$ & 3.67 & 183,385 & 944 & 936 & 859 & 5.01 & 230,603 & 1,006 & 1,127 & 1,000 \\
\hline & $+10 \%$ & 3.70 & 180,136 & 942 & 935 & 858 & 5.01 & 223,728 & 1,006 & 1,127 & 1,000 \\
\hline & $-10 \%$ & 3.83 & 166,623 & 936 & 934 & 856 & 5.01 & 196,227 & 1,006 & 1,127 & 1,000 \\
\hline & $-15 \%$ & 3.86 & 163,107 & 744 & 862 & 855 & 5.01 & 189,351 & 1,006 & 1,127 & 1,000 \\
\hline \multirow{4}{*}{$\theta$} & $+15 \%$ & 3.45 & 179,832 & 1,024 & 1,016 & 931 & 4.17 & 189,870 & 1,065 & 1,103 & 1,000 \\
\hline & $+10 \%$ & 3.55 & 185,359 & 997 & 990 & 908 & 4.45 & 194,216 & 1,049 & 1,109 & 1,000 \\
\hline & $-10 \%$ & 3.99 & 160,914 & 869 & 871 & 797 & 5.60 & Invalid & 936 & 1,159 & 1,000 \\
\hline & $-15 \%$ & 4.13 & 154,368 & 832 & 836 & 765 & 3.38 & Invalid & 884 & 1,188 & 1,000 \\
\hline \multirow{4}{*}{$R$} & $+15 \%$ & 3.76 & 174,332 & 937 & 934 & 856 & 5.01 & 211,502 & 1,005 & 1,127 & 1,000 \\
\hline & $+10 \%$ & 3.76 & 174,050 & 937 & 934 & 856 & 5.01 & 210,994 & 1,005 & 1,127 & 1,000 \\
\hline & $-10 \%$ & 3.77 & 172,920 & 937 & 934 & 856 & 5.01 & 208,961 & 1,005 & 1,127 & 1,000 \\
\hline & $-15 \%$ & 3.77 & 172,638 & 937 & 934 & 856 & 5.01 & 208,453 & 1,005 & 1,127 & 1,000 \\
\hline \multirow{4}{*}{$\pi$} & $+15 \%$ & 3.89 & 181,654 & 932 & 934 & 855 & 5.01 & 211,736 & 1,005 & 1,127 & 1,000 \\
\hline & $+10 \%$ & 3.85 & 179,039 & 933 & 934 & 855 & 5.01 & 211,150 & 1,005 & 1,127 & 1,000 \\
\hline & $-10 \%$ & 3.66 & 167,427 & 942 & 936 & 858 & 5.01 & 208,805 & 1,005 & 1,127 & 1,000 \\
\hline & $-15 \%$ & 3.60 & 164,176 & 946 & 937 & 860 & 5.01 & 208,219 & 1,005 & 1,127 & 1,000 \\
\hline
\end{tabular}

The amount of returned quantity for the case with all-units discount in all scenarios seems insensitive with respect to the changes in parameter values. Despite these changes, the optimal returned quantity is relatively the same, and in Scenario 2 and 3 these values are invalid due to the existence of at least one returned quantity of less than 1,000 units. This is also an indication that there is a limitation to increasing or decreasing the parameter values. Scenario 2 and Scenario 3 give an invalid total inventory cost for the case of all-units discount since at least one item has an order quantity of less than 10,000 units (or a returned quantity of less than 1,000 unit), with the exception of Scenario 2 when we decrease the deterioration rate by $10 \%$. This holds true for all parameter changes (holding cost, deteriorating rate, return cost per unit and backorder cost per unit).

In Scenario 4, the condition without all-units discount gives a lower total inventory cost compared to the condition with all-units discount. This means that condition without discount is preferable in order to minimize the total inventory cost than all-units discount condition. If we look further 
International Journal of Mathematical, Engineering and Management Sciences

Vol. 5, No. 3, 416-431, 2020

https://doi.org/10.33889/IJMEMS.2020.5.3.035

into Scenario 4, we can see that increasing or decreasing the holding cost and deterioration rate has a bigger effect on the total inventory cost compared to the return cost per unit and backorder cost. In this situation, based on the choice of parameter values of our model, it is better not to accept the all-units discount scheme offered by the supplier, reduce holding cost and try lowering the deterioration rate in order to minimize the total inventory cost.

\section{Conclusions and Further Research}

We have developed a mathematical model for the multi-item problem with inventory-dependent demand, return and all-units discount along with the algorithm to find the optimal solution. The multi-item problem here is relevant to the problem where most of small retailers have to deal in their daily operation. There are two decision variables considered in our model, the return time and the order quantity. The objective of our model is to minimize the total inventory cost. We also consider scenarios for the case of three items for individual and joint return time with and without all-units discounts. We found that individual return time gives a minimum total inventory cost in both cases with and without all-units discount. Individual return time with no discount is preferable compared to other scenarios since it gives more freedom to the retailer to return unsold or deteriorated item at its optimal return time. Also the all-units discount offered by the supplier is not quite attractive to the retailer to order more. We also perform a sensitivity analysis to study the impact of changes in parameter values from $-15 \%$ to $+15 \%$ on the optimal solution in each scenario. Only one parameter value changes, while the other parameter values are kept the same in each scenario. Some values of order quantities and total inventory costs become invalid since at least one of the order quantities is less than 10,000 units which is the price break in our all-units discount scheme. We found that in general as the holding cost, deterioration rate, return cost and backorder cost increase, the total inventory cost will also increase. In our scenarios, we found that individual return time with no discount gave the least total inventory cost. In practice, individual return time gives the retailer more freedom in returning the unsold (deteriorated) items to the supplier at its optimal return time. Also, all-units discount scheme offered by the supplier can lower the ordering and shortage cost but it cannot offset the return, holding and purchasing cost, making it unfavorable to the retailer. When considering only one item, we also found that the one with no all-units discount gives the least total inventory cost and shorter optimal return time compared with the one with all-units discount.

Our model can be extended in several directions such as considering stochastic deterioration, pricedependent demand, time-dependent demand, two-parameter Weibull deterioration and other discount schemes such as incremental discount. Considering all other possibilities in returning items by grouping items that will be jointly returned to the supplier is also a possible immediate suggestion for further research of this paper.

\section{Conflict of Interest}

The authors confirm that there is no conflict of interest to declare for this publication.

\section{Acknowledgements}

Research funding from the Directorate of Research and Community Services, Indonesian Directorate General of Higher Education (DP2M-DIKTI) and valuable comments from the reviewers are highly appreciated. 
International Journal of Mathematical, Engineering and Management Sciences

Vol. 5, No. 3, 416-431, 2020

https://doi.org/10.33889/IJMEMS.2020.5.3.035

\section{References}

Baker, R.C., \& Urban, T.L. (1988a). Single-period inventory dependent demand models. Omega, 16(6), 605607.

Baker, R.C., \& Urban, T.L. (1988b). A deterministic inventory system with an inventory-level-dependent demand rate. Journal of the Operational Research Society, 39(9), 823-831.

Chang, C.-T. (2004). Inventory models with stock-dependent demand and nonlinear holding costs for deteriorating items. Asia-Pacific Journal of Operational Research, 21(04), 435-446.

Chang, C.-T., Chen, Y-J., Tsai, T-R., \& Wu, S-J. (2010). Inventory models with stock- and price-dependent demand for deteriorating items based on limited shelf space. Yugoslav Journal of Operations Research 20(1), 55-69.

Duong, L.N.K., Wood, L.C., \& Wang, W.Y.C. (2015). A multi-criteria inventory management system for perishable \& substitutable products. Procedia Manufacturing, 2, 66-76.

Dye, C.Y. (2012). A finite horizon deteriorating inventory model with two-phase pricing and time-varying demand and cost under trade credit financing using particle swarm optimization. Swarm and Evolutionary Computation, 5, 37-53.

Filina-Dawidowicz, L., \& Postan, M. (2016). Optimal inventory control for perishable items under additional cost for deterioration reduction. LogForum, 12(2), 147-156.

Heizer, J., \& Render, B. (2014). Operation management sustainability and supply chain management. $11^{\text {th }}$ ed. Pearson, Boston.

Kaliraman, N.K., Raj, R., Chandra, S., \& Chaudhry, H. (2015). An EPQ inventory model for deteriorating items with Weibull deterioration under stock dependent demand. International Journal of Scientific \& Technology Research, 4(1), 232-236.

Kavithapriya, R., \& Senbagam, K. (2018). An EOQ inventory model for two parameter Weibull deterioration with quadratic time dependent demand and shortages. International Journal of Pure and Applied Mathematics, 119(7), 467-478.

Kumar S., Kumar P., \& Saini M. (2012). An order level inventory model for deteriorating items with quadratic demand rate and variable holding cost. Inernational Journal of Scientific Research Engineering and Technology, 1(5), 253-263

Levin, R.I., McLaughlin, C.P., Lamone, R.P., \& Kottas, J.F. (1972) Productions/Operations management: contemporary policy for managing operating systems. McGraw-Hill, New York.

Li, R., Lan, H., \& Mawhinney, J.R. (2010). A review on deteriorating inventory study. Journal of Service Science and Management, 3(1), 117-129.

Loedy, N., Lesmono, D., \& Limansyah, T. (2018, November). An inventory-dependent demand model with deterioration, all-units discount, and return. In Journal of Physics: Conference Series (Vol. 1108, No. 1, p. 012010). IOP Publishing.

Mishra, V.K., Singh, L.S., \& Kumar, R. (2013). An inventory model for deteriorating items with timedependent demand and time-varying holding cost under partial backlogging. Journal of Industrial Engineering International, 9(1), 1-5.

Nagare, M., \& Dutta, P. (2012). Continuous review model for perishable products with inventory dependent demand. In Proceedings of the International Multi-Conference of Engineers and Computer Scientists (Vol. 2, pp. 14-16). Hong Kong. ISBN: 978-988-19251-9-0.

Nahmias, S. (1982). Perishable inventory theory: a review. Operations Research, 30(4), 680-708. 
International Journal of Mathematical, Engineering and Management Sciences

Vol. 5, No. 3, 416-431, 2020

https://doi.org/10.33889/IJMEMS.2020.5.3.035

Pervin, M., Roy, S.K., \& Weber, G.W. (2018). Analysis of inventory control model with shortage under timedependent demand and time-varying holding cost including stochastic deterioration. Annals of Operations Research, 260(1-2), 437-460.

Prasad Patnaik, V.V.S., \& Patnaik, D.P. (2015). A numerical study on deterministic inventory model for deteriorating items with selling price dependent demand and variable cycle length. Jordan Journal of Mechanical \& Industrial Engineering, 9(3), 223-240.

Rathod, K.D., \& Bhathawala, P.H. (2013) Inventory model with inventory-level dependent demand rate, variable holding cost and shortages. International Journal of Scientific and Engineering Research, 4(8), 368-372.

Ray, J. (2017). Deterioration and its uncertainty in inventory systems. Global Journal of Pure and Applied Mathematics, 13(8), 4003-4014.

Russell, R.S., \& Taylor III, B.W. (2014). Operations and supply chain management. $8^{\text {th }}$ ed. International Student Version. Wiley, Singapore.

Setiawan, S.W., Lesmono, D., \& Limansyah, T. (2018). A perishable inventory model with return. IOP Conference Series: Materials Science and Engineering, 335, 012049. doi:10.1088/1757$899 X / 335 / 1 / 012049$.

Sharmila, D., \& Uthayakumar, R. (2015). Inventory model for deteriorating items involving fuzzy with shortages and exponential demand. International Journal of Supply and Operations Management, 2(3), 888-904.

Shenoy, D., \& Rosas, R. (2018) Problems \& solutions in inventory management. Springer, Switzerland.

Silver, E.A., \& Peterson, R. (1985) Decision systems for inventory management and production planning, $2^{\text {nd }}$ ed, Wiley, New York.

Singh, T., Mishra, P.J., \& Pattanayak, H. (2017). An optimal policy for deteriorating items with timeproportional deterioration rate and constant and time-dependent linear demand rate. Journal of Industrial Engineering International, 13(4), 455-463.

Tersine, R.J. (1994) Principles of inventory and materials management, $4^{\text {th }}$ ed., Prentice Hall, New Jersey.

Uthayakumar, R., \& Tharani, S. (2017). An economic production model for deteriorating items and time dependent demand with rework and multiple production setups. Journal of Industrial Engineering International, 13(4), 499-512.

Wolfe, H.B. (1968). A model for control of style merchandise. Industrial Management Review, 9(2), 68-82.

Yadav, R. K., \& Vats, A. K. (2014). A deteriorating inventory model for quadratic demand and constant holding cost with partial backlogging and inflation. IOSR Journal of Mathematics, 10(3), 47-52. 